Results 1310 infants were randomised, median gestation 28.0w, median birthweight $1010 \mathrm{~g}$ and median age starting the intervention $44 \mathrm{~h}$. No adverse events related to the intervention were reported.

\begin{tabular}{llll} 
Abstract 0-008 & Table 1 & & \\
\hline & B breve, $\mathbf{n = 6 5 0}$ & Placebo, $\mathbf{n}=660$ & Adjusted RR (95\% Cl) \\
NEC $\geq$ Bell stage 2 & $61(9.4 \%)$ & $66(10.0 \%)$ & $0.93(0.68$ to 1.27$)$ \\
LOS & $73(11.2 \%)$ & $77(11.7 \%)$ & $0.97(0.73$ to 1.29$)$ \\
Death & $54(8.3 \%)$ & $56(8.5 \%)$ & $0.93(0.67$ to 1.30$)$ \\
\hline
\end{tabular}

Conclusions This intervention was not associated with any advantage in this population of babies. This result highlights the need to assess the efficacy of different probiotic strains and challenges the validity of combining trials using different probiotic interventions in meta-analyses.

\section{0-009 LONGITUDINAL DEVELOPMENTAL EFFECTS OF THE INFANT BEHAVIOURAL ASSESSMENT AND INTERVENTION PROGRAM IN VERY LOW BIRTH WEIGHT INFANTS}

${ }^{1} \mathrm{~J}$ Van Hus, ${ }^{1} \mathrm{M}$ Jeukens-Visser, ${ }^{1} \mathrm{~K}$ Koldewijn, ${ }^{2} \mathrm{R}$ Holman, ${ }^{3} \mathrm{H}$ Kok, ${ }^{1} \mathrm{~F}$ Nollet, ${ }^{3} \mathrm{~A}$ Van Wassenaer-Leemhuis. ${ }^{1}$ Rehabilitation, Academic Medical Center, Amsterdam, Netherlands, ${ }^{2}$ Clinical Research Unit, Academic Medical Center, Amsterdam, Netherlands; ${ }^{3}$ Neonatology, Academic Medical Center, Amsterdam, Netherlands

\subsection{6/archdischild-2014-307384.76}

Background Cross-sectional analyses at 6, 12, 24 months and 5.5 years, revealed positive intervention effects on child development in VLBW infants who were supported by the Infant Behavioural Assessment and Intervention Program $\subset$ (IBAIP) as comparing to standard follow-up care. Longitudinal effects were not analysed yet.

AIM To investigate the longitudinal effects of the IBAIP in VLBW infants on cognitive and motor development.

Methods In a RCT, 86 VLBW infants received the IBAIP until 6 months CA, 90 VLBW infants received standard care. At 6, 12, and 24 months CA, cognitive and motor development were assessed with the Bayley Scales of Infant Development. At 5.5 years CA the Wechsler Preschool and Primary Scale of Intelligence and the Movement Assessment Battery for Children were used. Longitudinal data were analysed with linear mixed models in total group and three subgroups, using Z-scores generated from raw cognitive and motor scores.

Results A significant intervention effect $(0.4 \mathrm{SD})$ on motor development was found $(\mathrm{p}=0.006)$. On cognitive development, a non-significant intervention effect over time was found $(\mathrm{p}=$ 0.063). In children with bronchopulmonary dysplasia (BPD) significant intervention effects were found for both cognitive (effect=0.7SD; $p=0.019$ ) and motor (effect=0.9SD; p = 0.026 ) outcome. Maternal education hardly influenced intervention effects over time, but in children with combined biological and social risks a longitudinal intervention effect of $0.8 \mathrm{SD}$ was found on cognitive development $(\mathrm{p}=0.044)$.

Conclusion The IBAIP leads to improved motor development in VLBW infants, and in infants with BPD also to improved cognitive development, over a five years period after the intervention.
$0-009 a$

THE PAEDIATRIC OBSERVATION PRIORITY SCORE (POPS): OUTCOMES OF 24000 PATIENTS

${ }^{1} \mathrm{D}$ Roland, ${ }^{1} \mathrm{~F}$ Davies, ${ }^{2} \mathrm{~T}$ Coats. ${ }^{1}$ Paediatric Emergency Medicine Leicester Academic (PEMLA) Group, University Hospitals of Leicester NHS Trust, Leicester, UK; ${ }^{2}$ Cardiovascular Sciences, Leicester University, Leicester, UK

\subsection{6/archdischild-2014-307384.77}

Background The Paediatric Observation Priority Score (POPS) (see Figure) has been designed as a triage tool and illness identification system to aid disposition and discharge decisions.

Methods A unique data-collection method was set up whereby the key parameters of POPS were inputted onto a web-based data entry sheet. All children 0-15 presenting with any condition were included except those presenting straight to the resuscitation room. Data was collated with the hospital's Emergency Department Information System and information from inpatient hospital systems.

Results After data cleaning 24068 records were available for review between the period of August 2012 and December 2013. 2870 patients were admitted (11.9\%). The majority of patients (16475) were POPS 0 (Table 1) and of these 794 (4.8\%) were admitted to the hospital. Only 11 children discharged with POPS 0 returned to be admitted and required further definitive management. There was a correlation between initial POPS and average hospital stay (Pearsons correlation $-0.83, \mathrm{r} 2=0.92)$. The receiver operating characteristic (ROC) curve was 0.802 for POPS values sectioned into categories $\{0,1-2,3-4,5-7$ and $8+\}$ at predicting admission.

Conclusion POPS demonstrates utility as a patient safety system and a means to plan resources. The ROC is comparable with paediatric early warning scores systems utilised in Children's Emergency Departments. There are significant risks in managing the acutely ill child but the introduction of POPS may assist in reducing unnecessary admission and prevent episodes of missed or incorrect diagnosis.

\section{Abstract 0-009a Table 1}

\begin{tabular}{|l|l|l|}
\hline POPS & $\begin{array}{l}\text { Patients } \\
\text { Presenting }\end{array}$ & $\begin{array}{l}\text { Admissions } \\
\text { (Percentage) }\end{array}$ \\
\hline 0 & 16475 & $794(4.8 \%)$ \\
\hline 1 & 3110 & $552(17.7 \%)$ \\
\hline 2 & 1701 & $429(25.2 \%)$ \\
\hline 3 & 1050 & $302(28.8 \%)$ \\
\hline 4 & 707 & $248(35.1 \%)$ \\
\hline 5 & 471 & $219(46.5 \%)$ \\
\hline 6 & 311 & $167(53.7 \%)$ \\
\hline 7 & 140 & $87(62.1 \%)$ \\
\hline 8 & 67 & $46(68.7 \%)$ \\
\hline 9 & 28 & $19(67.9 \%)$ \\
\hline 10 & 5 & $4(80 \%)$ \\
\hline 11 & 2 & $2(100 \%)$ \\
\hline 12 & 1 & $1(100 \%)$ \\
\hline Total & 24068 & $2870(11.9 \%)$ \\
\hline
\end{tabular}

